\section{DP - 498}

Instruments

AEC Research and Development Report

AN ELECTRON MULTIPLIER AS A DETECTOR

FOR A SURFACE IONIZATION

MASS SPECTROMETER - DESIGN

by

L. Cathey

Applied Physics Division

August 1960
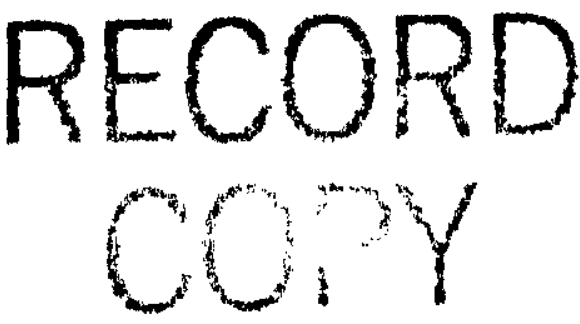

DO NOT RELEASE

FROM FILE

E. I. du Pont de Nemours \& Co.

Savannah River Laboratory

Aiken, South Carolina 
Th1s report was prepared as an account of Government sponsored work. Ne1ther the United States, nor the Commission, nor any person acting on behalf of the Commission:

A. Makes any warranty or representation, expressed or implied, with respect to the accuracy, completeness, or usefulness of the information contained in this report, or that the use of any information, apparatus, method, or process disclosed in this report may not infringe privately owned rights; or

B. Assumes any liabilities with respect to the use of, or for damages resulting from the use of any information, apparatus, method, or process disclosed in this report.

As used in the above, "person acting on behalf of the Commission" includes any employee or contractor of the Commission, or employee of such contractor, to the extent that such employee or contractor of the Commission, or employee of such contractor prepares, disseminates, or provides access to, any information pursuant to his employment or contract with the commission, or his employment with such contractor.

Printed in USA. Price $\$ 0.50$ Avallable from the office of Technical Services U. S. Department of Commerce Washington 25, D. C. 



\section{ABSTRACT}

A fourteen-stage electron multiplier has been used to amplify the detector signals in a surface Ionization mass spectrometer. The system can either measure the mult1plier anode current or count the anode pulses. Pulse counting may be used for signal currents in the range from $10^{-13}$ to $10^{-18}$ ampere. The range of the normal electrometer circuit is extended by the electron multiplier so that it measures currents from $10^{-10}$ to $10^{-15}$ ampere with a fast response. 


\section{CONTENTS}

\section{Page}

Introduction $\quad 4$

Summary 4

Discussion

Description of the Instrument 5

Multiplier Detector and Preamplifier 5

H1gh Voltage Power Supply 7

Pulse Ampliflers $\quad 12$

Discriminator $\quad 12$

Scaling System $\quad 14$

Count Rate Clrcuit 14

$\begin{array}{ll}\text { System Operation } & 16\end{array}$

$\begin{array}{ll}\text { Bibliography } & 18\end{array}$

\section{LIST OF FIGURES}

F1gure

1 Block Diagram of the System 5

2 Photographs of the Preamplifier and Multiplier 6

3 Circuit Diagram of the Preamplifier 8

$4 \quad$ Circuit Diagram of the High Voltage Supply 9

5 Photographs of the High Voltage Supply 10

6 Photograph of the High Voltage Regulator 11

7 Clrcuit Diagram of the Discriminator 12

8 Photographs of the Discriminator 13

9 Circuit Diagram of the Count Rate Circuit 14

10 Photographs of the Count Rate Clrcult 15

11 Gain Curves of the Multipliers 16

12 Physical Installation 17 


\title{
AN ELECTRON MULTIPLIER AS A DETECTOR FOR A SURFACE IONIZATION MASS SPECTROMETER - DESIGN
}

\author{
INTRODUCTION
}

The Consolidated Electrodynamics Corporation (CEC) Model 21-702 mass spectrometer at the Savannah River Laboratory is applied to Isotopic analysis of solid material with a surface ionization source. Among those materlals that are analyzed are some that are very radioactive. In order to keep the contamination of the drift tube to a minimum, it is desirable to operate the spectrometer with the weakest ion beam that w1ll allow accurate analysis.

The limiting feature of the mass spectrometer for weak ion beams is the sensitivity of the ion detector located beyond the analyzer slit of the spectrometer. If the ions that emerge from the analyzer slit are directed onto a suitable secondary emitting material, the secondary electrons may be amplified in an electron multiplier. Current amplifications as high as ten million times can thus be achleved with a very low noise background. The amplified pulse resulting from even one singly charged ion incident on the first surface can be counted. The precision of the sample analysis depends wholly on the beam current statistics and is not limited by the detector.

The use of an electron multiplier as detector for a mass spectrometer was one of the first applications of a multistage secondary emission amplifier. (1) While the technique is not new, until recent years counting clrcuits did not exist that were fast enough to allow significant dynamic range in such a detector when it is used as a counting device.

Multiplier gain stability is a problem in those mass spectrometers where the sample is introduced as a gas and the system pressure is above $10^{-6} \mathrm{~mm}$. Since the Savannah River Laboratory Model 2l-702 mass spectrometer analyses solids by means of a surface 1onization source, the pressure of the system is normally well below $10^{-6} \mathrm{~mm}$ of mercury and the multiplier stability is not affected by the residual pressure.

\section{SUMMARY}

A fourteen-stage electron multiplier was bulit and installed as detector in a CEC Model 21-702 mass spectrometer. The assoclated electronic circults were arranged so that pulse counting can be used for very weak ton beams in the range from $10^{-13}$ to $10^{-18}$ ampere. The pulse resolving time was about 66 millimicroseconds.

The direct current to the multiplier anode can be measured by a vibrating reed electrometer, for lon beams from $10^{-10}$ to $10^{-15}$ ampere. 
In addition, the lead to the first dynode of the multiplier was isolated so that ion beam currents could be measured directly.

\section{DISCUSSION}

\section{DESCRIPTION OF THE INSTRUMENT}

\section{MULTIPLIER DETECTOR AND PREAMPLIFIER}

The application of electron multipliers as the detectors for mass spectrometers is not new. (1) The detector described in this report can be assembled from available equipment with a minimum of effort.

The electronics assoclated with the electron multiplier has been designed so that the output signal may be measured as a direct current using an electrometer, or it may be counted as pulses in a pulse amplifier system. Utilization of both modes of operation gives a wide dynamic range to the detector system.

A block diagram of the system is shown in Figure 1 . The electrometer circuit is a standard Applied Physics vibrating reed electrometer, which was present in the CEC Model 21-702 system before the electron multiplier was added. As shown in Figure 1, the electrometer and the multiplier high voltage supply are the only units in use during a current measurement. When pulses are counted, the whole system is in use except for the electrometer.

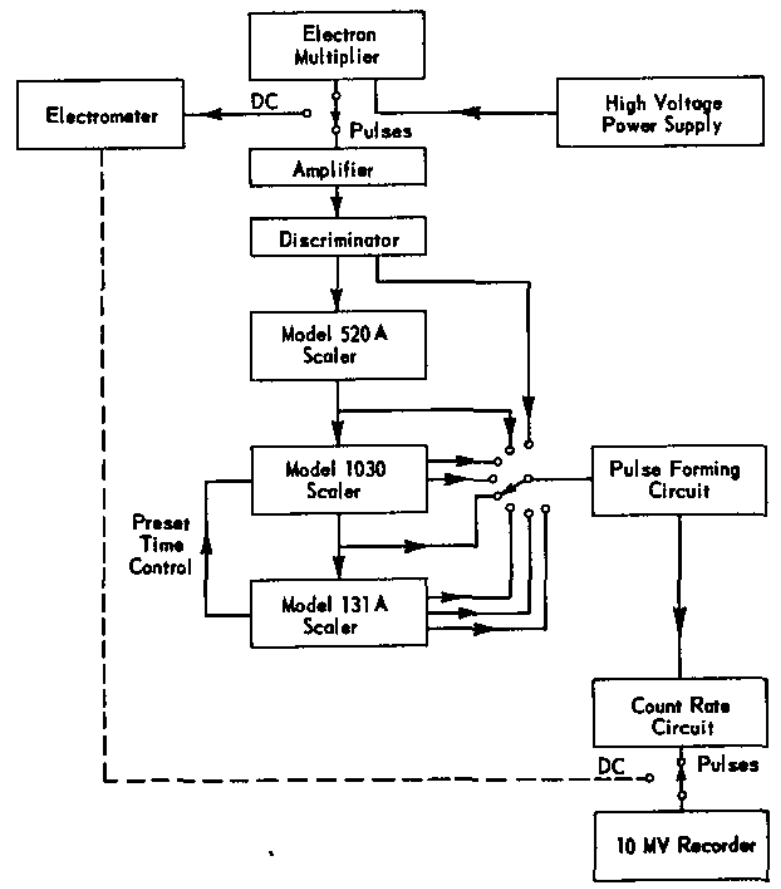

FIG. I BLOCK DIAGRAM OF THE SYSTEM 
A photograph of the multiplier and preamplifier housing is shown in Figure 2. The fourteen-stage multiplier has been assembled from the multiplier parts of DuMont 6292 photomultipliers. The dynodes used in the assembly were selected for uniformity of color of the oxidized sliver magneslum alloy in the nickel quadrants. The ceramic side supports for assembling the fourteen dynodes were sawed and joined in the Laboratory Glass Shop. The Glass Shop also made a special seventeen-pin tube press to support the multiplier and leads. The press was foined to the vacuum system flange with black sealing wax. Such a mount permits alignment of the multiplier in the fon beam.
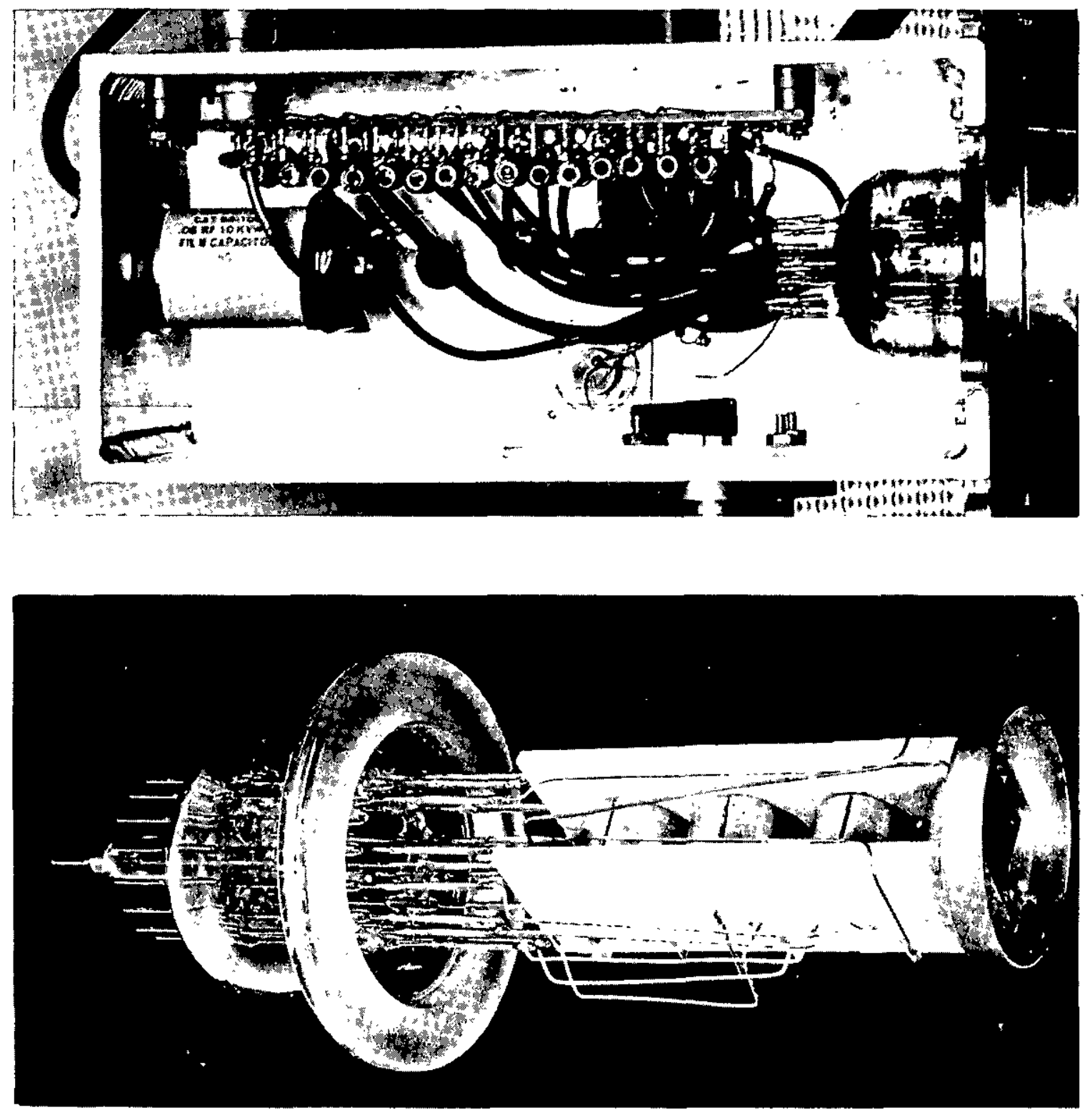

FIG. 2 PHOTOGRAPHS OF PREAMPLIFIER AND MULTIPLIER 
Two other electron multipliers using fourteen cusp-shaped dynodes of silver magnesium alloy were tried. It was not possible to achieve sufficient gain in these multipliers with total voltages less than 5 kllovolts on the string of divider resistors. No special activation process was used with any of the dynodes.

The lead to the first dynode of the multiplier was brought out of the isolated center electrode of the tube press seen in Figure 2. This allowed operation of the first electrodes of the multiplier as a Faraday cage for direct beam current measurement. A wire grid (0.005-inch nickel wires on $1 / 16$-inch centers) was placed across the shield electrode of the multiplier to reduce the number of secondary electrons that escape from the front of the multiplier. A 50\% transmission beam-measuring grid placed before the analyzer slit already existed in the mass spectrometer. The current from this grid before the slit is used to correct the current read in the detector for variations in the primary beam intensity. The currents before and after the analyzer slits may be compared by using the two current measurements.

Metal film resistors were selected for the dynode divider resistors shown in Figure 3 to reduce the noise generated at the preamplifier input. A value of 100,000 ohms was chosen so that the divider current would be about 2 milliamperes with about 3 kilovolts applied to the string. The high bleeder current permits multiplier anode currents of 1 microampere to be used without causing more than a $1 \%$ change in the gain of the multiplier system. If the maximum signal currents to be used are less than 1 microampere, the bleeder current may be reduced in proportion by increasing the resistance of the dynode resistors.

The anode load resistance of the multiplier is $1000 \mathrm{ohms}$. As shown in Figure 3, this is also the grid resistor of the preamplifier. The preamplifier is a single 6AK5 tube used as a cathode follower to match the impedance of the 200-ohm cable carrying the signal to the matn amplifiers. A filter system was placed in the supply leads to the preamplifier to keep nolse or signals in the later amplifier stages from entering the preamplifier housing on the supply wires.

\section{HIGH VOLTAGE POWER SUPPLY}

The current required for the bleeder chain of the multiplier is too great to be supplied by conventional oscliloscope power transformers since additional current is required to operate a glow tube regulator system. The total current required is of the order of 10 milliamperes. For efficient regulation, this current is supplied at a potential of 9 kilovolts. A conventional voltage doubler system that meets these requirements is shown in Figure 4 . The power transformer is avallable as a plate transformer in surplus IFF gear. There does 


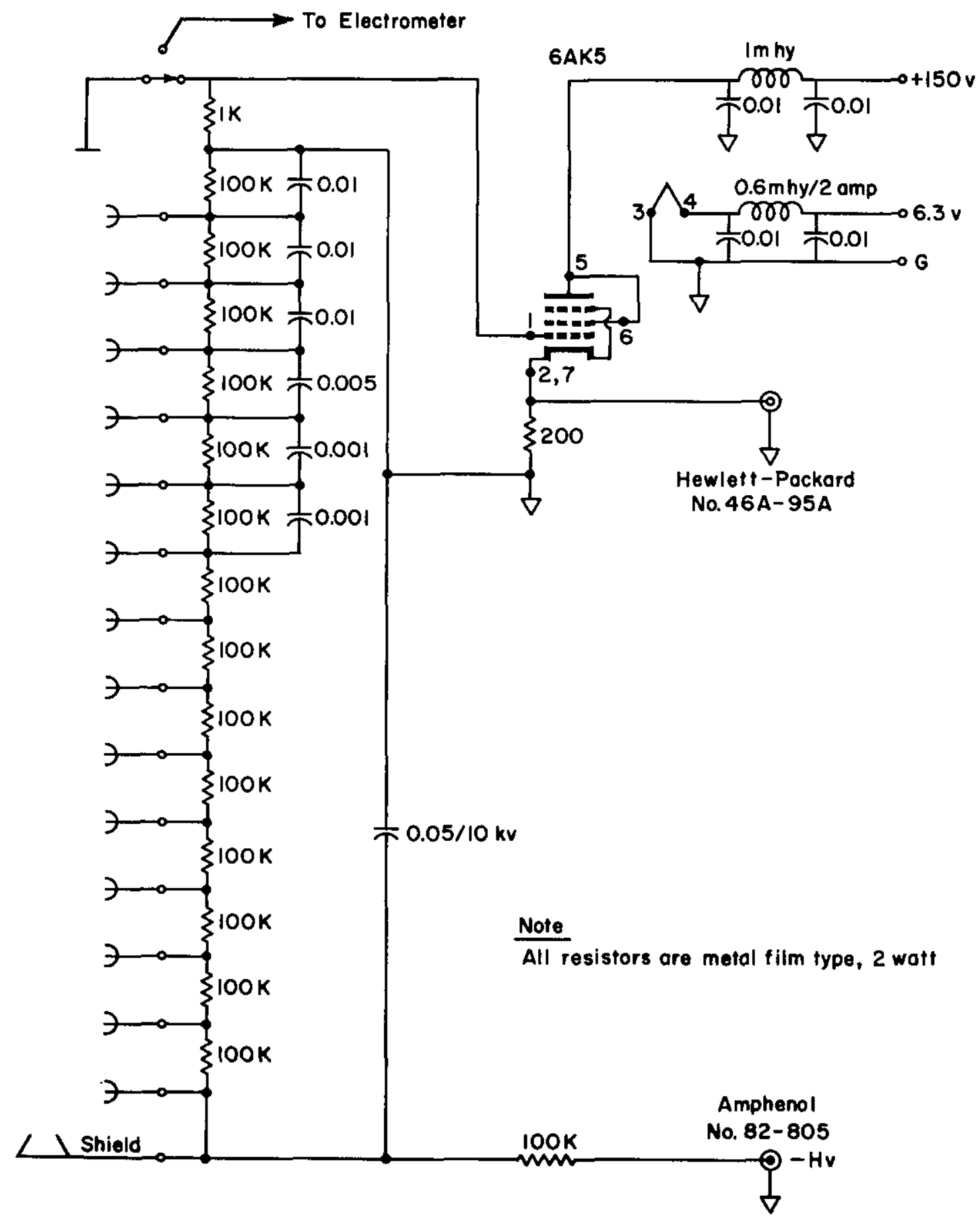

FIG. 3 CIRCUIT DIAGRAM OF THE PREAMPLIFIER 


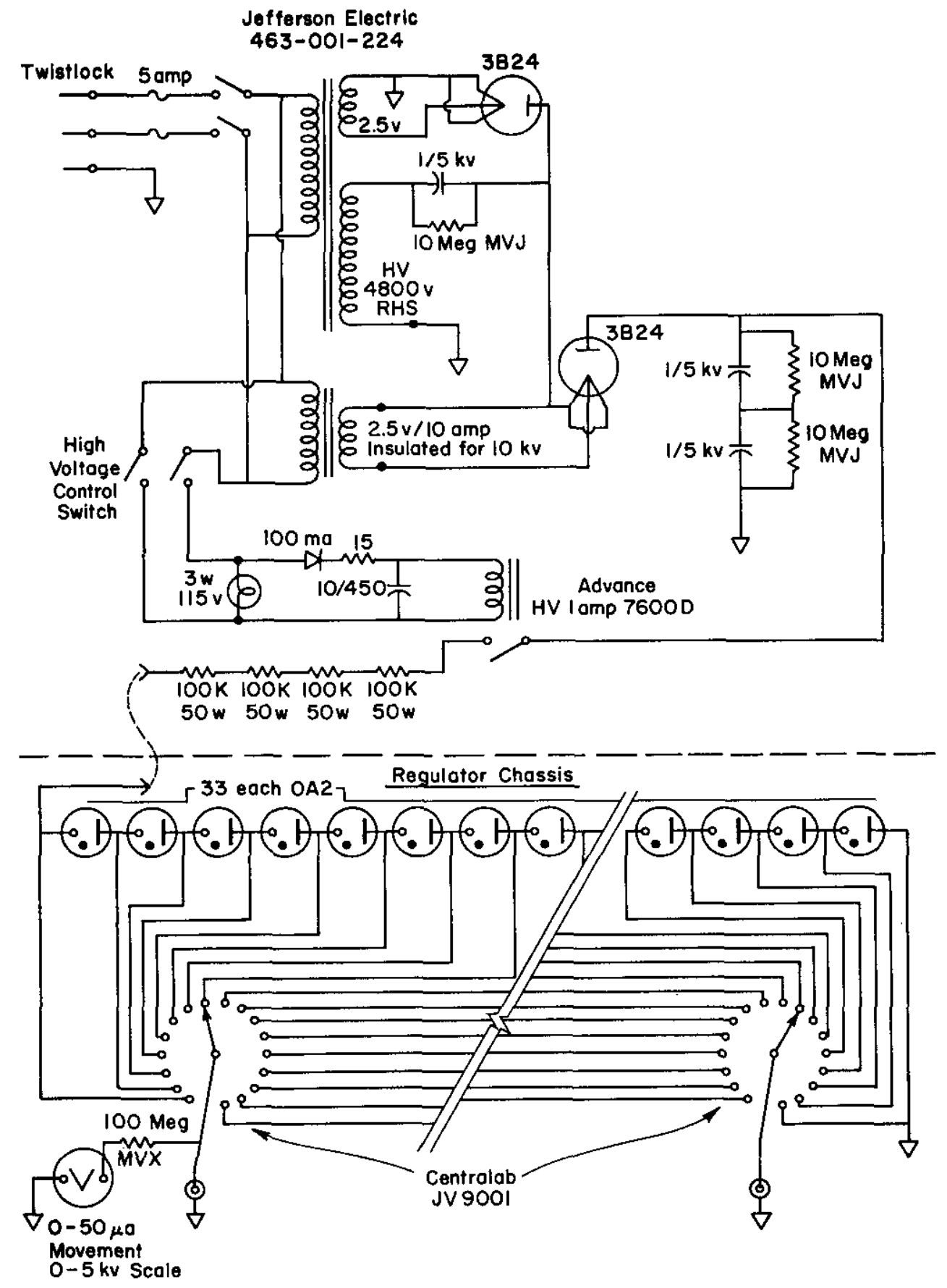

FIG. 4 CIRCUIT DIAGRAM OF THE HIGH VOLTAGE SUPPLY 
not appear to be any commerclal equivalent. The transformer operates at 4800 volts rms output and has been loaded to 20 milliamperes for half a day without noticeable heating. Photographs of the power supply are shown in Figure 5 .
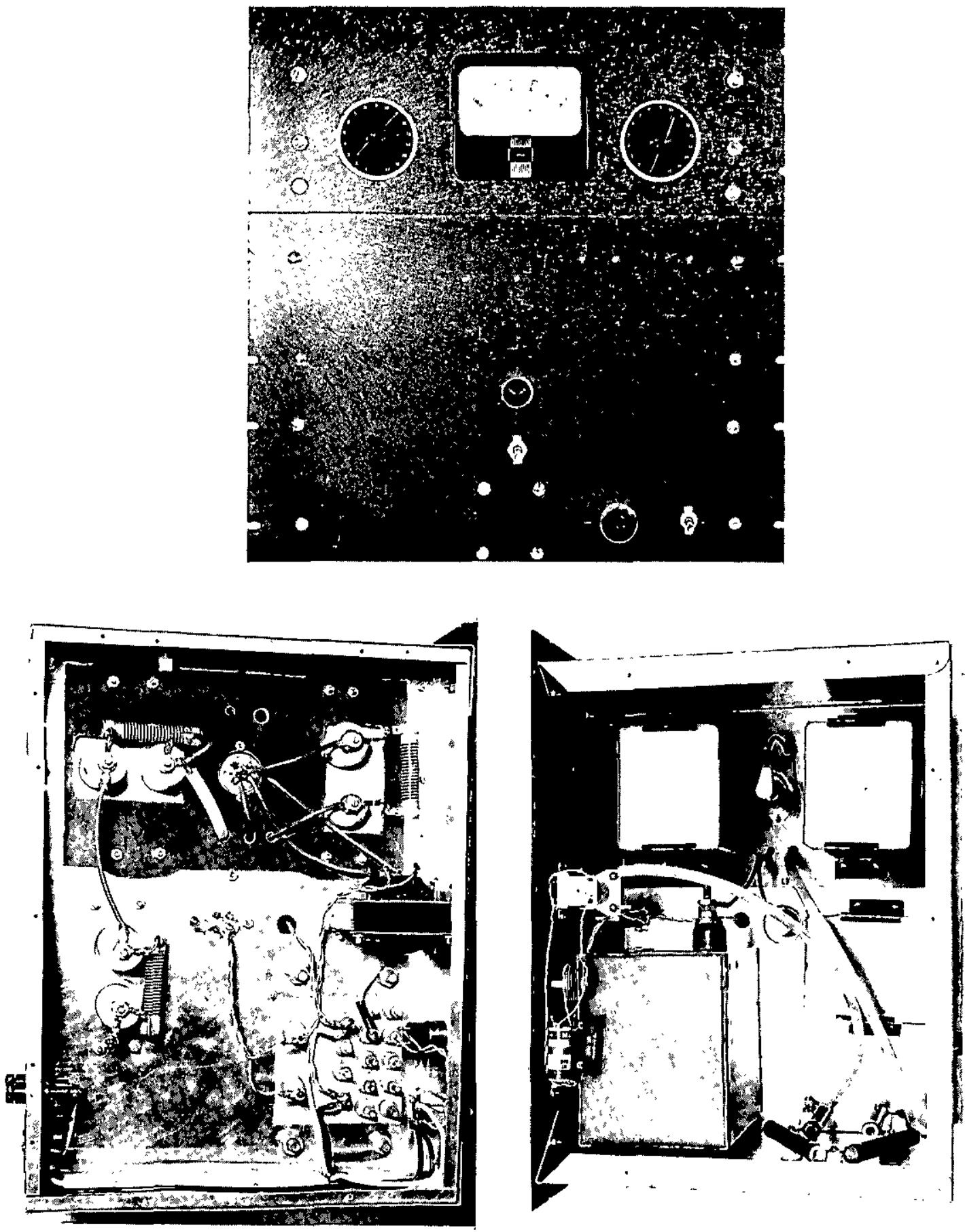

FIG. 5 PHOTOGRAPHS OF THE HIGH VOL TAGE SUPPLY 
The regulator is a string of 33 type $0 A 2$ glow regulator tubes. These are housed in a separate box, shown in Figure 6 , together with the voltmeter and selector switches. The selector switch mechanisms are insulated from ground and are driven through insulated couplings. The voltages are avallable at separate output connectors for the two switches. Th1s design permits the use of voltage selection swltches that are smaller than would be possible if the full 5000 volts were across one sw1tch.

The high voltage cable to the preamplifier housing is RG-1]/U cable. This use is somewhat above the published voltage rating of this cable, but the ratings are based on $A C$ voltages and this is $D C$ voltage.

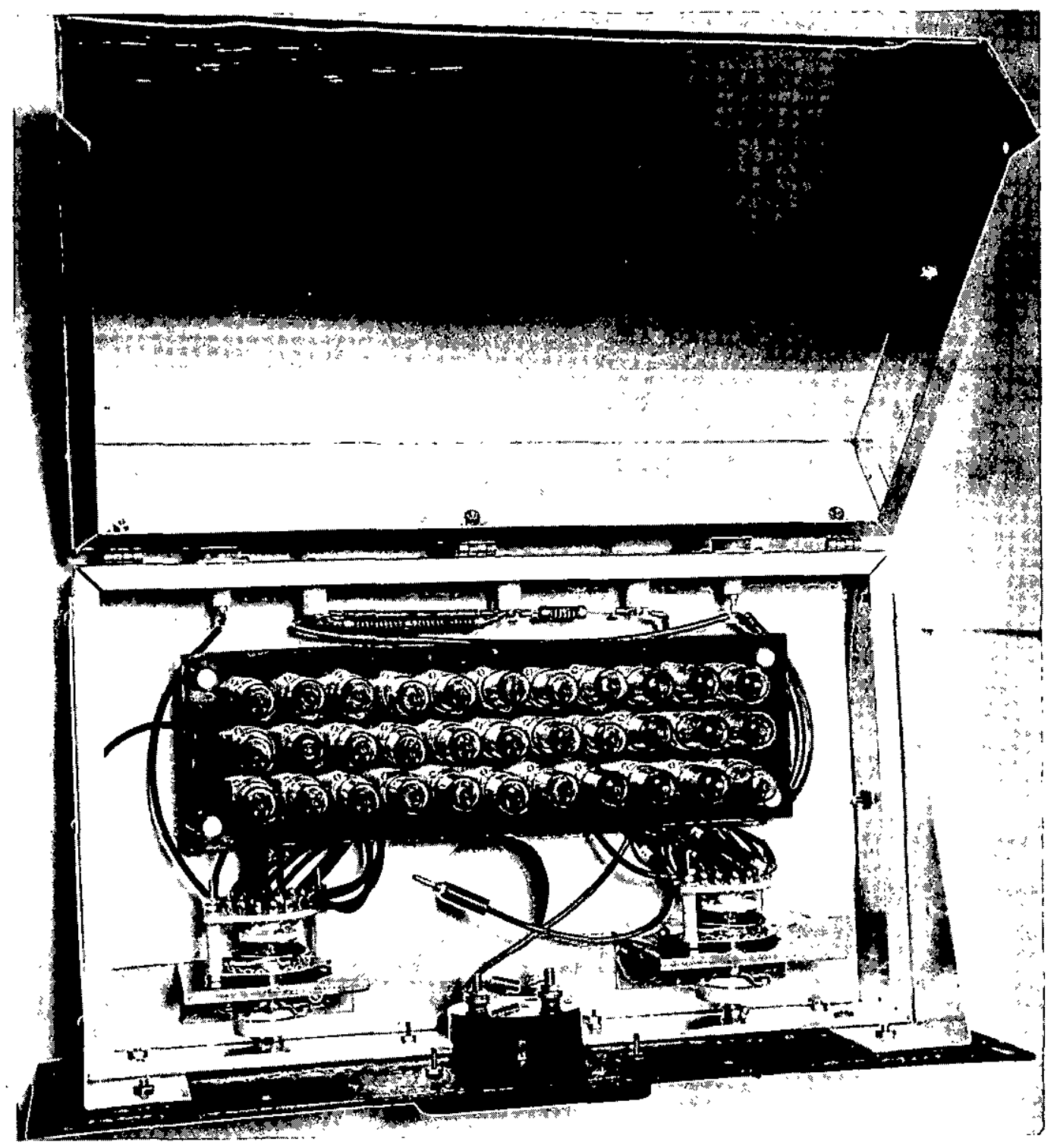

FIG. 6 PHOTOGRAPH OF THE HIGH VOLTAGE REGULATOR 


\section{PULSE AMPLIFIERS}

The main amplifier is made of Hewlett-Packard wide band amplifiers. There are four type 460B amplifiers and one Type 460A amplifier in the system. The position of the 460A amplifier in the string may be changed to achleve the best signal-to-no1se rat1o. The output of the last amplifier is fed to a millimicrosecond discriminator.

\section{DISCRIMINATOR}

The circuit diagram of the discriminator is shown in Figure 7 . A photograph of the chassis is shown in Figure 8. The circult is essentially the same as that published in the University of California Radiation Laboratory report UCRL-8569. (2) The circuit of the slow speed output given in the report has been changed so that pulses of the proper polarity and size are generated to drive a pulse forming circuit in the intermediate scaler. The fast output from the discriminator is fed to a Hewlett-Packard 10 megacycle scaler.

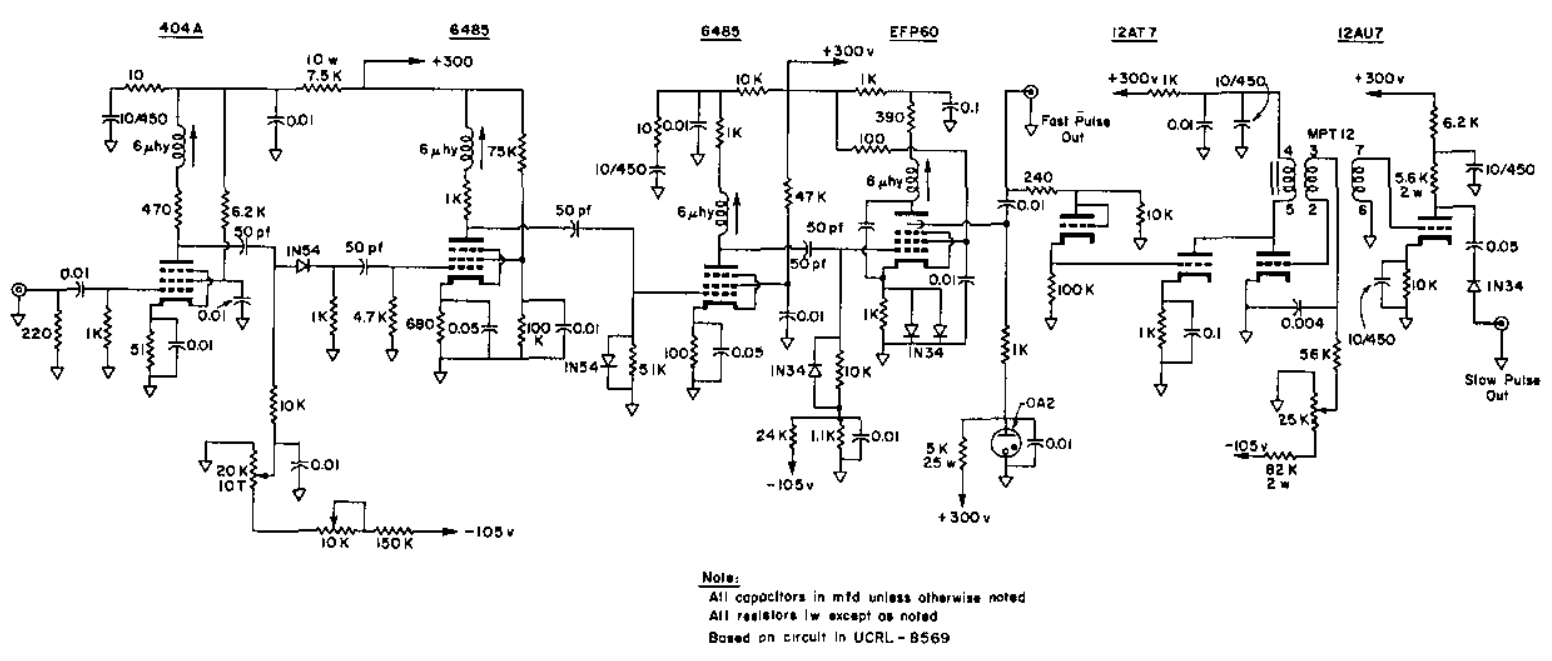

FIG. 7 CIRCUIT DIAGRAM OF THE DISCRIMINATOR 

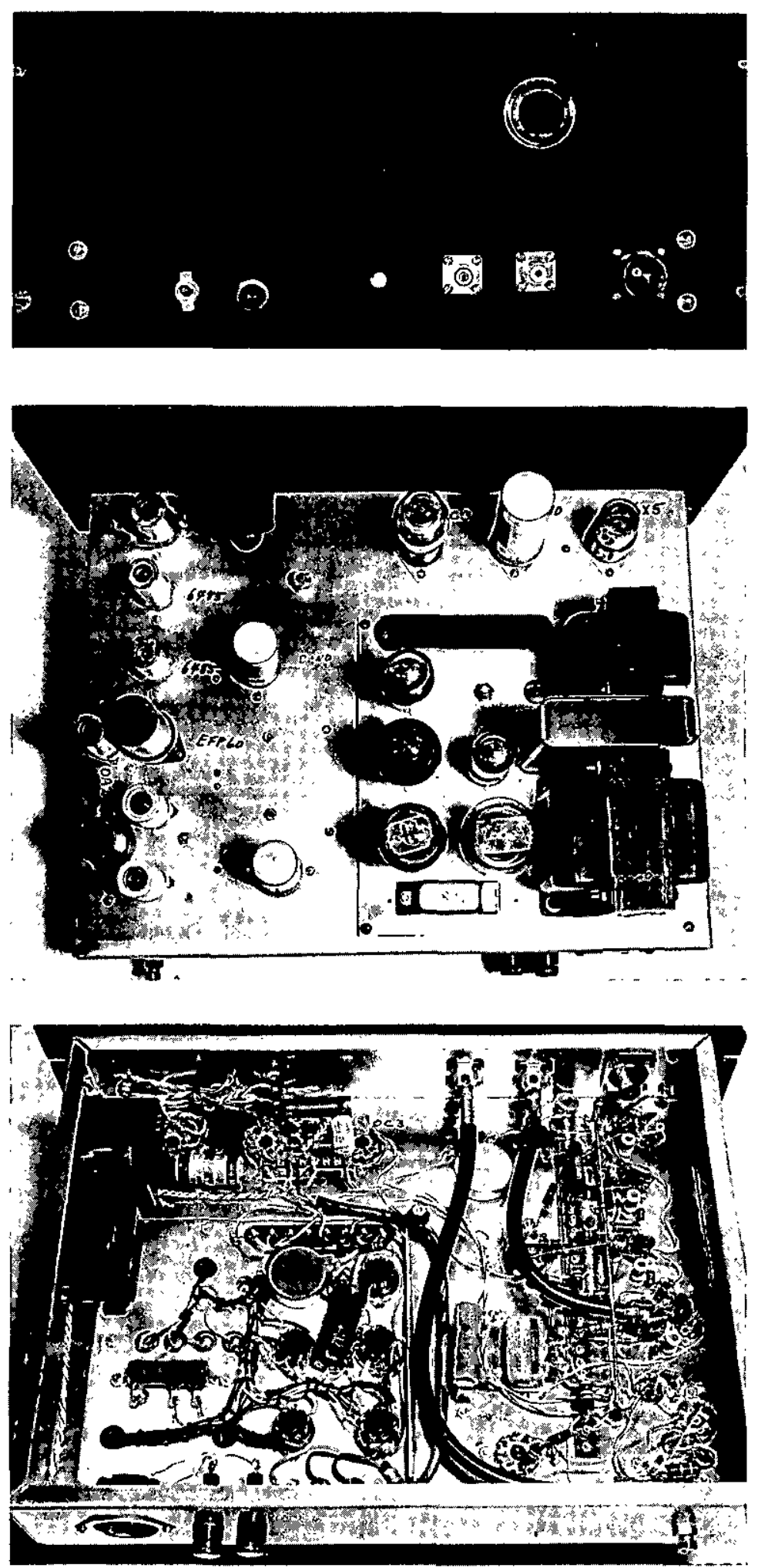

FIG. 8 PHOTOGRAPHS OF THE DISCRIMINATOR 
The scaling system is made in three units for a total scaling factor of 100,000,000 before the mechan1cal reg1ster. The first scaler is a Hewlett-Packara Model 520A scaler. This feeds pulses to an Atomlc Instrument Model 1030 scaler. The Model 1030 scaler has an upper count rate limit of 200 kllocycles. The last scaling unit is a Baird-Atomic Model 131A scaler with an upper limit on the input count rate of 20 kilocycles. The scaling system makes use of the preset time feature of the Model I3lA scaler to control the intermediate and slow scalers so that counting may be done for selected time intervals.

A selector switch is wired into the scaling system so that the transfer pulse between any pair of decades after the first two in the high speed scaler may be switched into the input of a count rate circuit. In addition, the slow pulse output from the discriminator is wired into this selector switch. For convenience the switch is located in the intermediate scaler. The register drive circuit of this scaler has been modified and it is used to supply pulses to the input of the count rate circuit.

\section{COUNT RATE CIRCUIT}

The diagram of the count rate circuit is shown in Figure 9 . The basic form of this circuit has been published previously in Savannah River Laboratory report DP-71.(3) Photographs of the unit are shown In Figure 10.

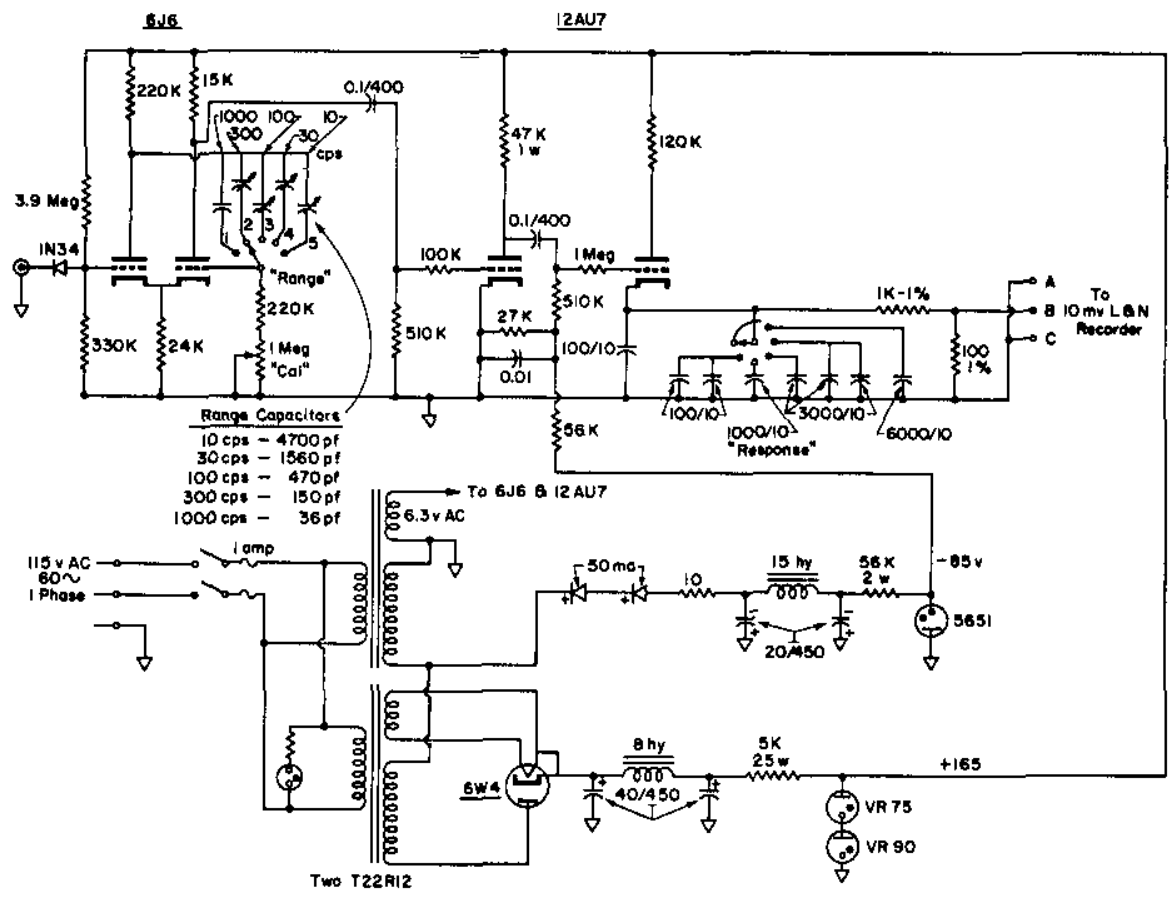

FIG. 9 CIRCUIT DIAGRAM OF THE COUNT RATE CIRCUIT 

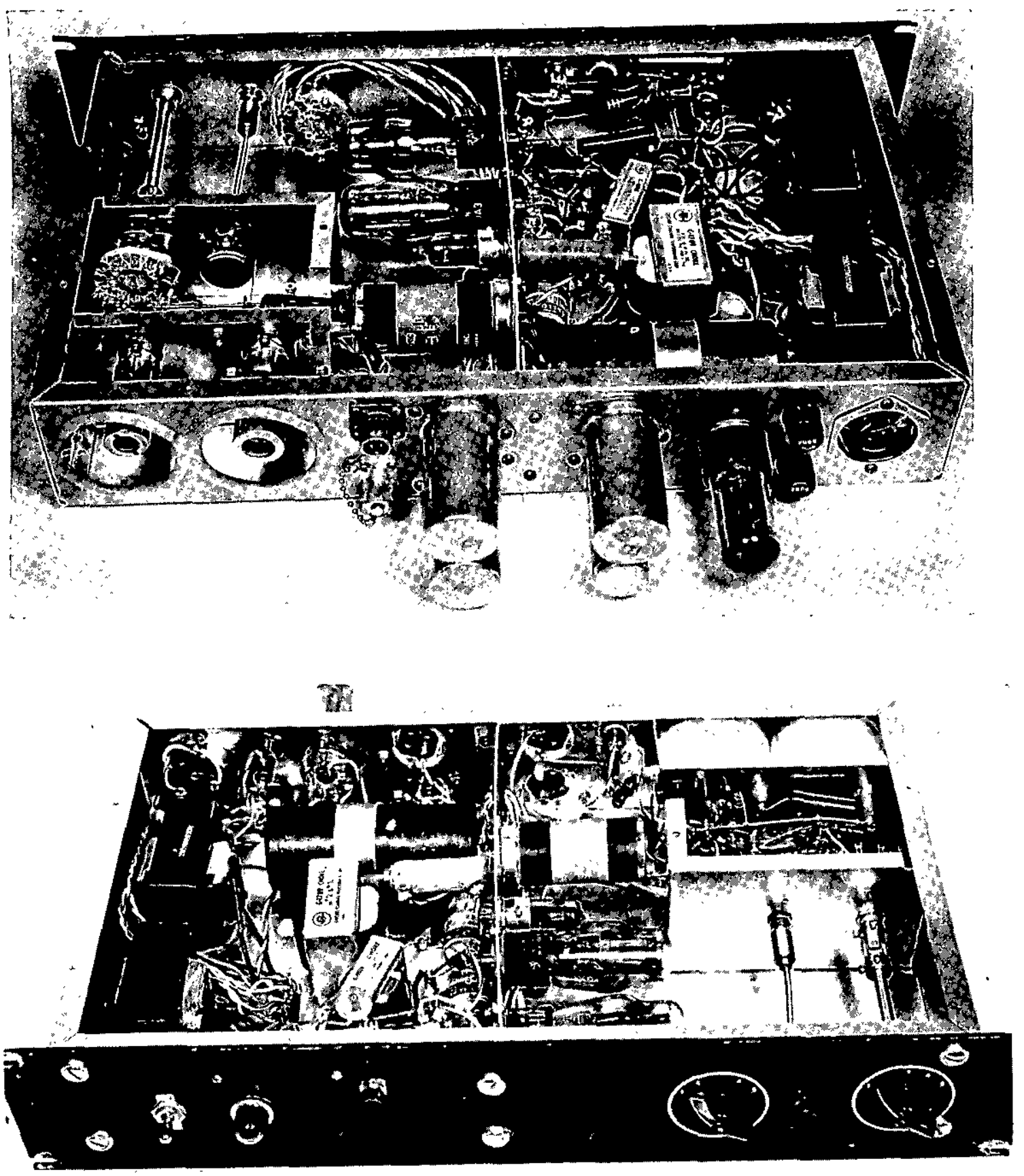

FIG. 10 PHOTOGRAPHS OF THE COUNT RATE CIRCUIT

The output of the count rate clrcult is fed to one channel of a 10 millivolt dual channel recorder. The other pen records the output of the Applied Physics vibrating reed electrometer that is connected to the grid before the slit in the detector housing of the spectrometer. Two traces are thus recorded. One trace indicates the current of 1ons passing through the analyzer slit, whlle the second trace indicates the total beam current at that instant. 
The operation of the equipment w1ll be discussed in a Savannah River Laboratory report to be 1ssued. (4) It 1 s of interest, however, to compare the gain of the box and cusp types of electron multipliers. A graph of the multiplier gain versus the total voltage applied to the divider string is shown in Figure 1l. Notice that the box dynodes glve a much higher gain.

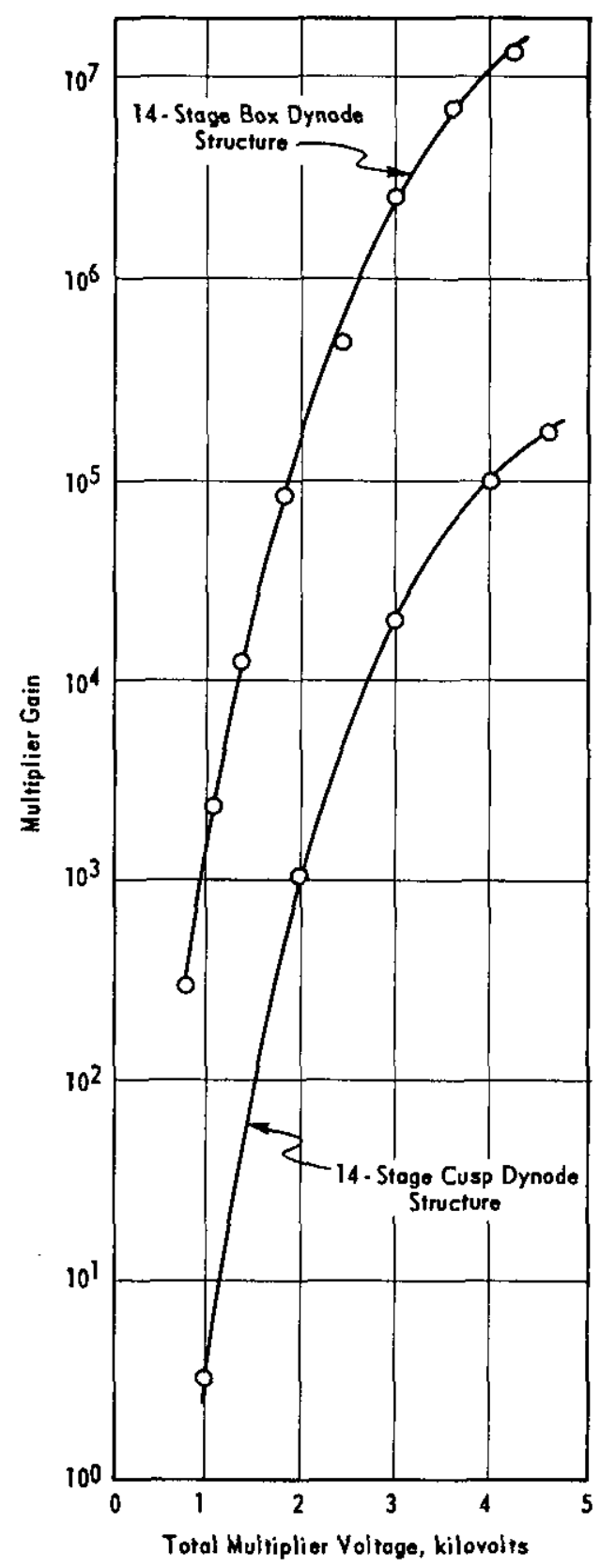

FIG. 11 GAIN CURVES OF THE MULTIPLIERS 
A photograph of the entire system is shown in Figure 12. The electronics of the electron multiplier system are assembled in the rack between the magnet and the control console. The three scalers and the count rate circuit are on top of the control console.

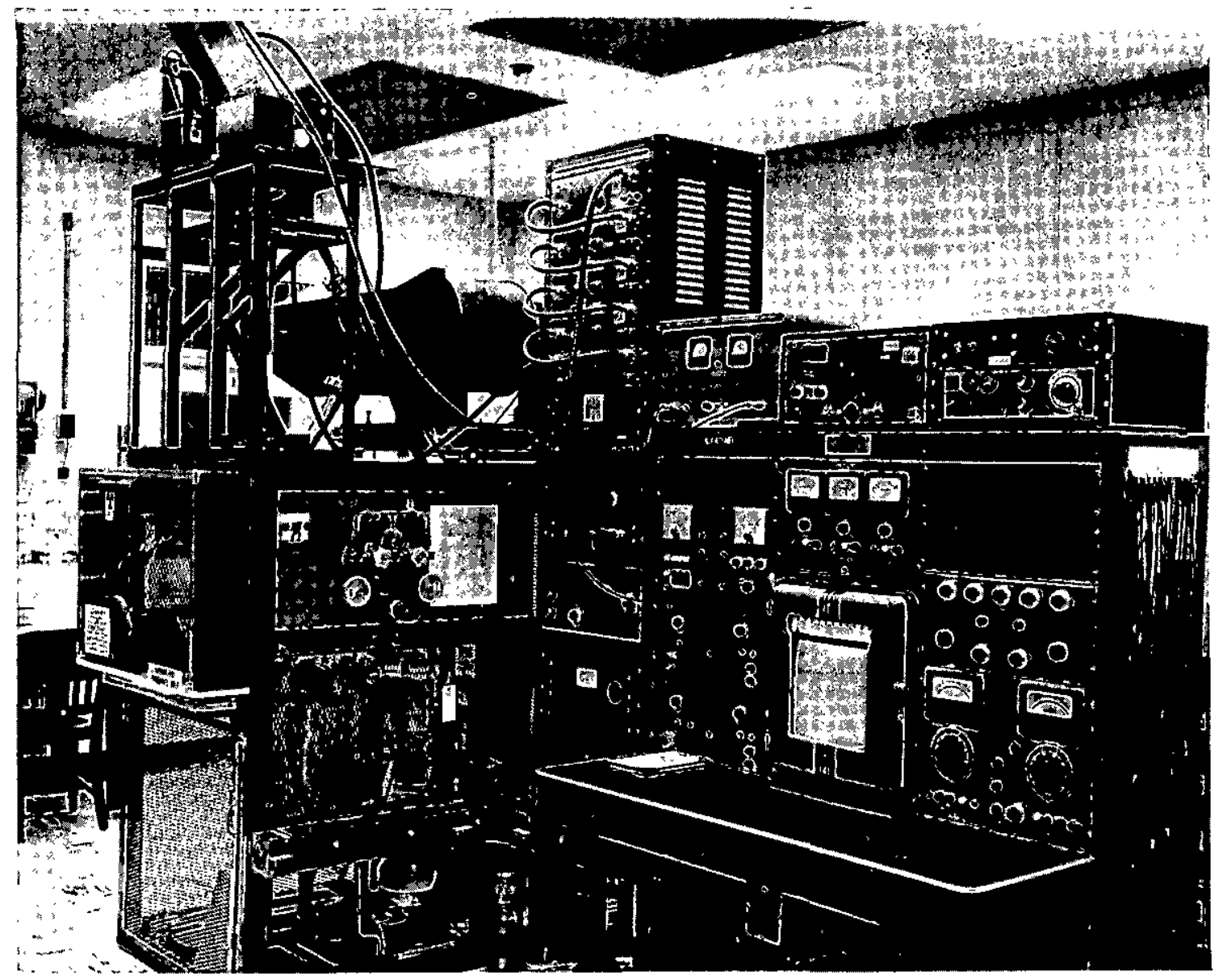

FIG. 12 PHYSICAL INSTALLATION

The pulse counting equipment and a Tektronix Model 517 osc1lloscope made it possible to measure the shape of the output pulse from the multiplier. A single charged ion incident on the first dynode of the multiplier caused a pulse at the anode that had a rise time of about 20 milimicroseconds and a decay time of about 30 millimiroseconds. The measured resolving time of the counting system was 66 millimicroseconds.

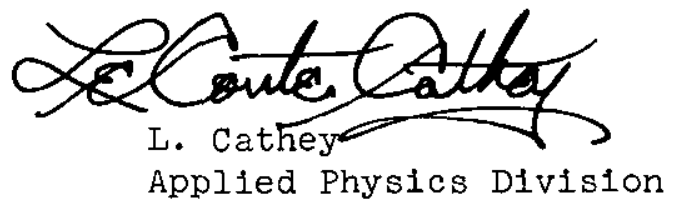




\section{BIBLIOGRAPHY}

1. Allen, J. S. "The Detection of Single Positive Ions, Electrons and Photons by a Secondary Emission Multiplier". Phys. Rev. 55, 966-71 (1939).

2. Swift, D. F. and V. Perez-Mendez. Millimicrosecond

Discriminator. Lawrence Radiation Lab., Univ. of California, Berkeley. AEC Research and Development Report UCRL-8569, $12 \mathrm{pp}$. (1958).

3. Cathey, L. A Count Rate Circult with a Grounded output. E. I. du Pont de Nemours \& Co., Alken, S. C. AEC Research and Development Report DP-71, 10 pp. (1954).

4. Chastagner, P. J. An Electron Multiplier as a Detector for a Surface Ionization Mass Spectrometer - Performance. E. I. du Pont de Nemours \& Co., Alken, S. C. (to be Issued as an AEC Research and Development Report DP- ). 